\title{
10-Year Changes in Adiposity in Cameroon School-Age Children: Evidence for Increasing Central Adiposity and Higher Adiposity Levels in Tallest-for-Age Children
}

\author{
Lifoter K. Navti $\mathbb{D}^{1,2,3}$ and Brice U. S. Foudjo ${ }^{1,3,4}$ \\ ${ }^{1}$ Department of Biochemistry, The University of Bamenda, P.O. Box 39,Bambili, Bamenda, Cameroon \\ ${ }^{2}$ Department of Biochemistry, Catholic University of Cameroon (CATUC), Bamenda P.O. Box 782, Bamenda, Cameroon \\ ${ }^{3}$ Nutrition and Health Research Group (NHRG), Bamenda, Cameroon \\ ${ }^{4}$ Association Sahelienne de Recherche Appliquee Pour le Developpement Durable (ASRADO), P.O. Box 2449, Djamena, Chad
}

Correspondence should be addressed to Lifoter K. Navti; knavti@gmail.com

Received 19 June 2021; Accepted 4 October 2021; Published 15 October 2021

Academic Editor: Aron Weller

Copyright (C) 2021 Lifoter K. Navti and Brice U. S. Foudjo. This is an open access article distributed under the Creative Commons Attribution License, which permits unrestricted use, distribution, and reproduction in any medium, provided the original work is properly cited.

\begin{abstract}
Objective. To examine changes in measures of adiposity and determine the prevalence of excess adiposity in relation to height in school children between 2010 and 2020. Methods. 5-12-year-old urban school-age children participated in two cross-sectional surveys in 2010 $(n=1274)$ and $2020(n=1550)$. Standard procedures were used for anthropometric measurements. Changes in BMI, waist circumference (WC), and waist-to-height ratio (WHtR) and the corresponding proportions of children with excess adiposity were analyzed and adjusted for design variables (class and school type) and age. Children were classified according to quartiles of height z-score and prevalence of excess adiposity estimated across each quartile. Results. There was a $2.4 \%$ and $3.3 \%$ increase in adjusted mean BMI and WC, respectively, between 2010 and 2020. The prevalence of central overweight/obesity (WC) and WHtR $\geq 0.5$ increased by $7.3 \%$ $\left(X^{2}=27.151, p<0.001\right)$ and $5.3 \%\left(X^{2}=26.117, p<0.001\right)$, respectively, between the two surveys except BMI overweight/obesity. The odds of excess adiposity significantly increased in 2020 for central overweight/obesity (WC) (OR 2.8, 95\% CI 2.0-3.6) and WHtR $\geq 0.5$ (OR 1.8, 95\% CI 1.3-2.4) and not for BMI overweight/obesity (OR 1.3, 95\% CI 0.8-1.7). The prevalence of BMI overweight/obesity significantly increased from $33 \%$ in 2010 to $51.5 \%$ in 2020 in the fourth quartile of height $z$-score $\left(X^{2}=19.198, p<0.001\right)$. Similarly, the prevalence of central overweight/obesity (WC) significantly increased from $23.5 \%$ in 2010 to $42.4 \%$ in 2020 in the fourth quartile of height $\mathrm{z}$-score $\left(X^{2}=18.733, p<0.001\right)$. Conclusion. Central overweight/obesity has increased more than BMI overweight/obesity over the last decade. Children with a higher height-for-age tend to accumulate more adiposity. Objective monitoring of adiposity levels and height of children is needed in future to identify groups for targeted intervention and prevention of chronic diseases.
\end{abstract}

\section{Introduction}

The increase in the number of overweight/obese children is reaching alarming proportions worldwide and has become an important aspect of global health [1]. Recent evidence from developed countries is showing that the number of children affected with overweight/obesity has plateaued [2]. However, overweight/obesity is increasing at a faster rate in developing countries [3]. This is because the developing countries are undergoing a rapid nutrition transition characterized by increasing income, changes in eating habits, and lifestyle [4]. A recent report indicates that 330 million children between the ages of 5 and 19 years were overweight/obese worldwide in 2016 [5]. Also, a recent review has indicated a transition to higher proportions of overweight/obesity among school-age children in sub-Saharan Africa [6]. The rapid increase is of concern because overweight/obesity in childhood has been shown to be associated with adverse health outcomes including arterial stiffness [7], hypertension [8], type 2 diabetes in adulthood, and coronary artery diseases later in life [9].

Cameroon is a low-income country, and no efforts have been made towards achieving the nutrition targets that concern overweight/obesity, which had been endorsed by the WHO [5]. The distribution of overweight/obesity in the 
country varies by the administrative region. For instance, recent studies in the Littoral and North West Regions among school-age children have shown prevalence estimates of $14.4 \%$ [10] and $17.6 \%$ [11], respectively. In the North West Region (NWR), the highest prevalence of overweight/obesity had been recorded amongst the tallest children [11]. Also, a recent nationwide survey indicated that the highest prevalence of overweight/obesity in children is in the Grassfield area of the country that includes the North West Region and West Region [12]. To the best of our knowledge, no study has been carried out in Cameroon to show changes in adiposity levels in school-age children over time.

Many studies that have assessed trends in overweight/ obesity have relied on BMI as a measure of adiposity, which has shortcomings. For instance, in monitoring changes in body composition of children over time, it is unclear whether increases in BMI observed are due to increase in lean body mass, increase in fat mass, or both [13]. Also, a previous report indicated that BMI can misclassify a high proportion of children with high body fat because of its low sensitivity [14]. Waist circumference (WC) and waist-toheight ratio (WHtR) are becoming important measures of adiposity in children. There is evidence suggesting that central adiposity (estimated by WC) has a stronger association with adverse health outcomes than adiposity estimated using BMI [15]. Also, WHtR, which is independent of age and gender, has been shown to be more sensitive in predicting risk factors of cardiovascular diseases than BMI [16]. In addition, a study had suggested that WHtR is an easy-to-use measure of central adiposity, and it would prevent the misclassification of many muscular children as overweight/obese that occurs when BMI is used [17]. This study was undertaken to examine recent trends in BMI, WC, and WHtR and determine the prevalence of excess adiposity in relation to stature in two samples of school children between 2010 and 2020 in the NWR of Cameroon.

\section{Materials and Methods}

2.1. Study Participants. Data for the current repeated crosssectional study were obtained from two surveys on schoolage children carried out in 2010 and 2020 in the North West Region (NWR) of Cameroon. A total of 2824 (1274 in 2010 and 1550 in 2020) children from three subdivisions in Mezam Division of the NWR between the ages of 5 and 12 years were included in the analysis. The sampling procedure was in two stages: firstly, for each survey, three primary schools were randomly selected in each subdivision from a list of primary schools obtained from the Regional Delegation of Basic Education of the NWR and invited to participate in the study. These primary schools included public, private, and faith-based schools. Secondly, within each school, $40 \%$ of children were randomly selected from one class in each target year of study.

This study set out to report on changes in the proportions of overweight/obese school-age children between 2010 and 2020. In 2010, the prevalence of overweight/obesity was $16.6 \%$. The sample size was calculated using $p 1=0.166$ and $p 2=0.266$ in order to be able to detect a $10 \%$ difference in the prevalence of overweight/obesity between the two surveys with $80 \%$ power and using the statistical significance cutoff of 0.05 . The sample size was also adjusted to reflect the inequality of the number of participants in the two surveys [18]. In order to adjust for the correlation of measures of children in the same school, the sample size was inflated. The details of the sample are shown in Figure 1.

2.2. Ethical Considerations. Approval to carry out this study was granted by the Institutional Review Board (IRB) of the Catholic University of Cameroon (CATUC), Bamenda (Ref. no. 12/CATUC-IRB/2019). Administrative clearance was obtained from the Regional Delegation of Public Health of the North West Region. Written informed consent and verbal assent were obtained from all head teachers/parents/ guardians/and children, respectively, before data collection commenced.

\section{Data Collection}

3.1. Anthropometry. Data collection was on school premises during physical education lessons. The same apparatus and the same protocol were followed in the two surveys by welltrained teachers. However, the schools that participated were different in the two surveys.

Height without shoes was measured using a portable stadiometer (Seca 213, Hamburg, Germany) to the nearest $0.1 \mathrm{~cm}$. A digital scale (Omron BF511, Kyoto, Japan) was used to measure body weight to the nearest $0.1 \mathrm{~kg}$. BMI was calculated from the height and weight of the children and recorded in $\mathrm{kg} / \mathrm{m}^{2}$. Waist circumference was measured as recommended by McCarthy et al. [19] using a nonelastic flexible tape (Seca 201, Germany). The z-scores of height, weight, and BMI were calculated using WHO AnthroPlus, a growth monitoring software for children between the ages of 5 and 19 years, which makes use of the WHO 2007 growth reference data [20]. Waist circumference was also adjusted for age and gender using the McCarthy waist circumference reference data for UK children [19]. Children were classified as overweight/ obese (BMI) according to WHO criteria [20]. The $91^{\text {st }}$ centile was used to define central overweight/obesity (WC) according to McCarthy references for WC [19]. WHtR was calculated by dividing the WC (in centimeters) by the height (in centimeters). Based on the fact that excessive upper body fat accumulation poses a health risk, WHtR was used to classify the study participants as "low risk" (<0.5) and "high risk" ( $\geq 0.5)$ [21]. In both surveys, all anthropometric measurements were carried out in duplicates and the average value was calculated and recorded. For reliability analysis, a two-way random-effects model was used to calculate intraclass (intraevaluator) correlation coefficients of anthropometric variables. In 2010, the intraclass correlation coefficients for height, weight, and WC were $>0.94,>0.97$, and $>0.94$, respectively. In 2020, the intraclass correlation coefficients were $>0.97,>0.96$, and $>0.96$ for height, weight, and waist circumference, respectively. 


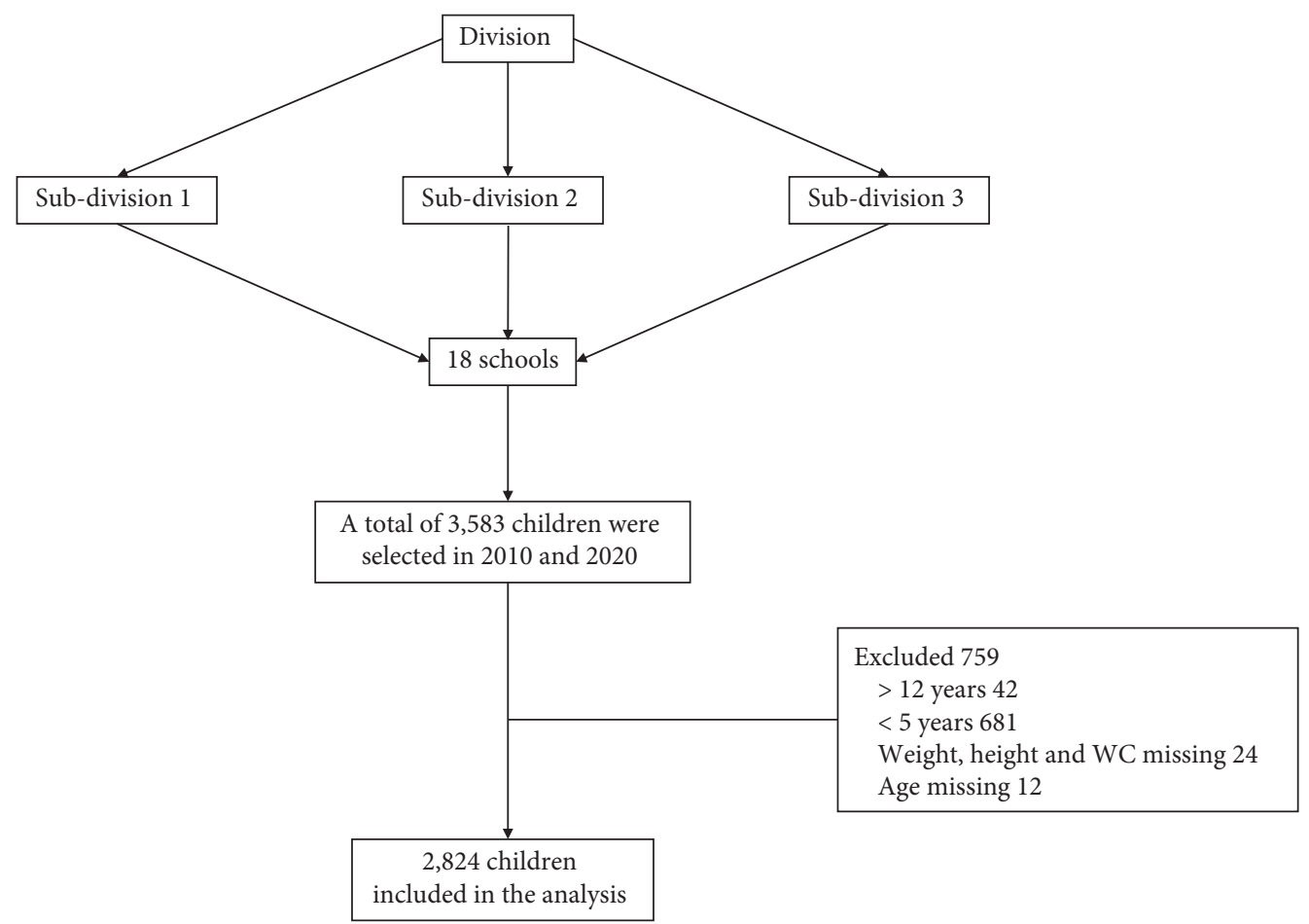

FIGURE 1: Flowchart of the sampling procedure/cleaning of data.

3.2. Statistical Analysis. All statistical procedures were carried out using IBM-SPSS for Windows version 21.0 (IBM Corporation Armonk, NY, USA). The prevalence by survey period was estimated using generalized linear models adjusting for design variables (class and school type) and age. Differences in proportions were compared using the chi-square test. Changes in means of anthropometric variables between the two survey periods were tested using linear regression analysis, with and without adjusting for design variables and age. Odds ratios of the different measures of adiposity were calculated using binary logistic regression analysis adjusting for age and the design variables.

The study participants were then classified into quartiles of height $\mathrm{z}$-score, and prevalence was calculated across each quartile to assess whether the proportion of overweight/ obese (BMI) and central overweight/obese (WC) children is increasing with an increase in quartiles of height $\mathrm{z}$-score. The prevalence, mean differences of anthropometric variables, and odds ratios have been presented with their corresponding 95\% confidence limits.

Statistical significance was set at $p<0.05$.

\section{Results}

The descriptive characteristics of the school-age children included in this analysis are presented in Table 1. There were significant $(p<0.05)$ differences in the distribution of participants according to age group, gender, and quartiles of height $\mathrm{z}$-score between the two survey periods. However, a significant difference was not observed when study participants were classified according to school type $(p>0.05)$.
TABLE 1: Descriptive characteristics of the study population.

\begin{tabular}{lrrrrr}
\hline & \multicolumn{2}{c}{2010} & \multicolumn{2}{c}{2020} & \\
Variable & $N=1274$ & \multicolumn{2}{c}{$N=1550$} & $p$ value \\
& $n$ & $\%$ & $n$ & $\%$ & \\
\hline Age group (years) & & & & & $<0.001$ \\
$5-6$ & 266 & 20.8 & 448 & 29.0 & \\
$7-8$ & 376 & 29.5 & 442 & 28.5 & \\
$9-10$ & 488 & 38.3 & 392 & 25.3 & \\
$11-12$ & 146 & 11.4 & 266 & 17.2 & \\
\hline Gender & & & & & 0.006 \\
Female & 638 & 50.1 & 694 & 44.8 & \\
Male & 636 & 49.9 & 856 & 55.2 & \\
\hline School type & & & & & 0.182 \\
Public & 642 & 50.4 & 742 & 47.9 & \\
Private/faith-based & 632 & 49.6 & 808 & 52.1 & \\
\hline Quartiles of height SDS & & & & & $<0.001$ \\
First quartile & 440 & 34.5 & 290 & 18.7 & \\
Second quartile & 282 & 22.1 & 436 & 28.1 & \\
Third quartile & 274 & 21.5 & 416 & 26.8 & \\
Fourth quartile & 278 & 21.8 & 408 & 26.3 & \\
\hline
\end{tabular}

Table 2 shows results of linear regression analysis, which was used to assess changes in means of anthropometric variables between the two surveys without adjusting and after adjusting for design variables and age. Over the 10-year period, the adjusted analysis indicates that the mean BMI and mean WC of the whole sample significantly increased by $2.4 \%$ and $3.3 \%$, respectively. On a gender basis, the mean increase in BMI was slightly higher for males (2.9\%) than that for females $(2.4 \%)$. However, over the 10 -year period, the increase in mean WC was higher in females $(3.4 \%)$ than 
TABLE 2: Means of the anthropometric parameters of study participants between 2010 and 2020.

\begin{tabular}{|c|c|c|c|c|c|c|c|c|c|c|}
\hline \multirow{3}{*}{ Variables } & \multicolumn{7}{|c|}{ Unadjusted analysis } & \multicolumn{3}{|c|}{ Adjusted analysis* } \\
\hline & \multicolumn{2}{|r|}{2010} & \multicolumn{2}{|r|}{2020} & \multirow{2}{*}{$\begin{array}{c}\text { Mean } \\
\text { difference }\end{array}$} & \multirow{2}{*}{$95 \% \mathrm{CI}$} & \multirow{2}{*}{$p$ value } & \multirow{2}{*}{$\begin{array}{c}\text { Mean } \\
\text { difference }\end{array}$} & \multirow{2}{*}{$95 \% \mathrm{CI}$} & \multirow{2}{*}{$\begin{array}{c}p \\
\text { value }\end{array}$} \\
\hline & Mean & 95\% CI & Mean & $95 \% \mathrm{CI}$ & & & & & & \\
\hline $\begin{array}{l}\text { Whole sample } \\
\text { BMI }\left(\mathrm{kg} / \mathrm{m}^{2}\right)\end{array}$ & & & & & & & & & & \\
\hline $\begin{array}{l}\text { BMI }\left(\mathrm{kg} / \mathrm{m}^{2}\right) \\
\text { BMI z-score }\end{array}$ & $\begin{array}{l}17.0 \\
0.19\end{array}$ & $\begin{array}{l}(16.8-17.2) \\
(0.12-0.27)\end{array}$ & $\begin{array}{l}17.3 \\
0.32\end{array}$ & $\begin{array}{l}(17.1-17.5) \\
(0.23-0.41)\end{array}$ & $\begin{array}{c}0.3 \\
0.13\end{array}$ & $\begin{array}{c}(-0.0-0.5) \\
(0.00-0.25)\end{array}$ & & $\begin{array}{c}0.4 \\
0.15\end{array}$ & $\begin{array}{r}(0.2-0 . \\
(0.03-0 .\end{array}$ & $\begin{array}{l}0.001 \\
0.017\end{array}$ \\
\hline $\mathrm{WC}(\mathrm{cm})$ & 58.0 & $(57.6-58.5)$ & 59.5 & $(58.9-60.1)$ & 1.5 & $(0.7-2.2)$ & $<0.001$ & 1.9 & & $<0.001$ \\
\hline WC z-score & 0.34 & $(0.28-0.4$ & 0.54 & (0.47-0 & & (0.09-0 & & & & $<0.001$ \\
\hline WHtR & 0.442 & $(0.440-0.445)$ & 0.441 & $(0.438-0.445)$ & & $(-0.006-0.003)$ & & -0.003 & $(-0.007-0.002)$ & 0.242 \\
\hline Height (cm) & 131.5 & $(130.6-132.5)$ & 135.3 & $(134.2-136.4)$ & 3.8 & $(2.3-5.2)$ & $<0.001$ & 5.2 & & $<0.001$ \\
\hline Height $\mathrm{z}$-score & -0.12 & $(-0.22--0.01)$ & 0.83 & $(0.76-0.90)$ & 0.95 & $(0.83-$ & $<0$. & 0.94 & $(0.8$ & $<0.001$ \\
\hline Weight (kg) & 30.0 & $(29.3-30.7)$ & 32.6 & $(31.8-3$ & 2.6 & $(1.5$ & $<0.0$ & 3.6 & & $<0.001$ \\
\hline Weight $\mathrm{z}$-score & -0.03 & $-0.1-0.03)$ & 0.69 & $(0.61-$ & & $(0.61$ & & 0.73 & & $<0.001$ \\
\hline \multicolumn{11}{|l|}{ Females } \\
\hline BMI $\left(\mathrm{kg} / \mathrm{m}^{2}\right)$ & 16.9 & $(16.7-17.2)$ & 17.2 & $(16.9-17.4)$ & 0.2 & $(-0.1-0.6)$ & 0.242 & 0.4 & $(0.1-0.7)$ & 0.026 \\
\hline BMI z-score & 0.28 & $(0.18-0.38)$ & 0.27 & $(0.15-0$ & -0.01 & $(-0.18$ & & 0.02 & $(-0.1$ & 0.837 \\
\hline $\mathrm{WC}(\mathrm{cm})$ & 58.2 & $(57.5-58.8)$ & 59.6 & $(58.8-60.5)$ & 1.4 & $(0.3$ & 0.0 & 2.0 & & $<0.001$ \\
\hline WC $\mathrm{z}-\mathrm{s}$ & 0.31 & $(0.22$ & 0.54 & & & & & & & 0.002 \\
\hline WHtR & 0.443 & $(0.439-0.446)$ & 0.444 & $(0.439-0.4$ & 0.001 & $(-0.006$ & 0.7 & -0.001 & $(-0.00$ & 0.859 \\
\hline Height (cm) & 131.8 & $(130.5-133.2)$ & 134.6 & $(133.3-136.1)$ & 2.8 & $(0.8$ & 0.00 & 4.7 & & $<0.001$ \\
\hline Height $\mathrm{z}-$ & -0.12 & $(-0.26-0.02)$ & 0.76 & $(0.66-0.85)$ & 0.88 & $(0.71-1.04)$ & $<0.001$ & 0.87 & $(0.71-1$ & $<0.001$ \\
\hline Weight (kg) & 30.0 & $(29.1-30.9)$ & 32.1 & & 2.1 & & & 3.2 & & $<0.001$ \\
\hline Weight $\mathrm{z}$-score & -0.07 & $(-0.10--0$. & 0.62 & $(0.51-c$ & 0.6 & $(0.56$ & & 0.70 & $(0.57-0$ & $<0.001$ \\
\hline \multicolumn{11}{|c|}{ Males } \\
\hline BMI $\left(\mathrm{kg} / \mathrm{m}^{2}\right)$ & 17.0 & $(16.8-17.3)$ & 17.4 & $(17.1-17.7)$ & & $(-0.07-0.76)$ & & 0.5 & $(0.1-0.8)$ & $<0.018$ \\
\hline BMI z-score & 0.17 & $(0.10-0.23)$ & 0.30 & $(0.25-0.44)$ & 0.13 & $(0.07-0.27)$ & 0.003 & 0.14 & $(0.08-0.29)$ & 0.001 \\
\hline $\mathrm{WC}(\mathrm{cm})$ & 57.9 & $(57.2-58.5)$ & 59.4 & $(58.6-60.1)$ & 1.5 & & & 1.8 & & $<0.001$ \\
\hline WC z-score & 0.37 & $(0.27-0.48)$ & 0.54 & $(0.42-0.65)$ & 0.16 & $(0.01-0.31)$ & 0.040 & 0.17 & $(0.02$ & 0.032 \\
\hline WHtR & 0.442 & $(0.438-0.446)$ & 0.438 & $(0.433-0.442)$ & -0.004 & $(-0.010-0.001)$ & 0.139 & -0.005 & $(-0.011-0.000)$ & 0.063 \\
\hline Height $(\mathrm{cm})$ & 131.2 & $(129.9-132.5)$ & 136.1 & $(134.5-137.7)$ & 4.9 & $(2.8-6.9)$ & $<0.001$ & 5.9 & $(4.9-7.0)$ & $<0.001$ \\
\hline Height $\mathrm{z}$-score & -0.11 & $(-0.26-0.03)$ & 0.92 & $(0.82-1.02)$ & 1.04 & $(-1.43--0.87)$ & $<0.001$ & 1.03 & $(0.85-1.21)$ & $<0.001$ \\
\hline Weight (kg) & 30.0 & $(29.0-30.9)$ & 33.2 & & 3.2 & & & 4.0 & & $<0.001$ \\
\hline Weight $\mathrm{z}$-score & 0.00 & $(-0.12-0.13)$ & 0.77 & $(0.65-0.88)$ & 0.77 & $(0.60-0.94)$ & $<0.001$ & 0.77 & $(0.60-0.94)$ & $<0.001$ \\
\hline
\end{tabular}

$\mathrm{CI}$; confidence interval, * adjusted for age, class, and school type.

that in males (3.1\%). Nevertheless, no significant changes in WHtR were observed between the two surveys. Table 2 also shows that the children were significantly taller and had a higher body weight in 2020 than 2010 .

Table 3 shows the prevalence according to BMI, WC, and WHtR for 2010 and 2020. For the whole sample, there was no significant change in the prevalence of BMI overweight/ obesity between 2010 and $2020\left(X^{2}=0.665, p=0.415\right)$. However, there was an overall $7.3 \%$ increase in the prevalence of central overweight/obesity (WC) between 2010 and 2020 , and this was statistically significant $\left(X^{2}=27.151\right.$, $p<0.001)$. On a gender basis, the increase in central overweight/obesity (WC) was $7.0 \%\left(X^{2}=15.058, p<0.001\right)$ and $8.5 \%\left(X^{2}=14.962, p<0.001\right)$ for males and females, respectively.

Also, there was an overall 5.3\% increase in the prevalence of WHtR $\geq 0.5$ ("high risk") between 2010 and 2020 $\left(X^{2}=26.117, p<0.001\right)$. In addition, the proportion of those at "high risk" (WHtR $\geq 0.5)$ increased by $5.6 \%\left(X^{2}=16.371\right.$, $p<0.001)$ and $5.1 \%\left(X^{2}=11.312, p=0.002\right)$ for males and females, respectively.

Figure 2 shows that the odds of central overweight/ obesity (WC) and odds of being at "high risk" (WHtR $\geq 0.5)$ significantly $(p<0.001)$ increased in 2020 when compared to 2010 as reference. However, the odds of BMI overweight/ obesity did not increase significantly.

The odds of having a higher BMI, WC, and WHtR changed over time when analyzed on a gender basis. For instance, in 2020, females had higher odds of being overweight/obese according to BMI [OR 2.36, CI (1.65-3.38), $p<0.001]$ and WC [OR 2.89, CI (1.83-5.51), $p<0.001]$ when compared to 2010. However, the odds of being at "high risk" according to WHtR was not significant for females [OR 1.94, CI (0.96-3.94) $p=0.066$ ]. Also, in 2020, males had higher odds of being overweight/obese according to BMI [OR 2.59, CI (1.78-3.76), $p<0.001$ ] and being at "high risk" according to WHtR [OR 3.79, CI (1.88-8.75), $p=0.001]$ when compared to 2010. However, the odds of being centrally overweight/obese according to WC was not significant for males [OR 1.41, CI (0.94-2.11), $p=0.094]$.

When the study participants were classified according to quartiles of height $\mathrm{z}$-score, the mean height in 2010 for the first, second, third, and fourth quartiles of height $\mathrm{z}$-score was $124.7 \mathrm{~cm}, 131.0 \mathrm{~cm}, 133.4 \mathrm{~cm}$, and $137.1 \mathrm{~cm}$, respectively. In 2020, the mean height for the first, second, third, and fourth 
TABLE 3: Prevalence of BMI overweight/obesity, central overweight/obesity, and $\mathrm{WHtR} \geq 0.5$ over time.

\begin{tabular}{lccccccccc}
\hline & & \multicolumn{3}{c}{2010} & \multicolumn{3}{c}{2020} \\
& Status & \multicolumn{2}{c}{ Males $(N=636)$} & \multicolumn{2}{c}{ Females $(N=638)$} & \multicolumn{2}{c}{ Males $(N=856)$} & \multicolumn{2}{c}{ Females $(N=694)$} \\
& & $\%$ & $(95 \% \mathrm{CI})$ & $\%$ & $(95 \% \mathrm{CI})$ & $\%$ & $(95 \% \mathrm{CI})$ & $\%$ & $(95 \% \mathrm{CI})$ \\
\hline \multirow{2}{*}{ BMI z-score } & Overweight & 15.1 & $(12.5-18.1)$ & 13.2 & $(10.8-16.0)$ & 15.4 & $(13.2-17.9)$ & 14.1 & $(11.7-16.9)$ \\
& Obesity & 1.9 & $(1.1-3.3)$ & 3.1 & $(2.0-4.8)$ & 2.8 & $(1.9-4.1)$ & 3.2 & $(2.1-4.8)$ \\
\hline \multirow{2}{*}{ WC z-score } & Overweight & 8.5 & $(6.6-10.9)$ & 12.2 & $(9.9-15.0)$ & 11.9 & $(9.9-14.3)$ & 15.9 & $(13.3-18.8)$ \\
& Central obesity & 0.9 & $(0.4-2.0)$ & 3.8 & $(2.5-5.5)$ & 4.4 & $(3.3-6.0)$ & 8.6 & $(6.8-10.9)$ \\
\hline \multirow{2}{*}{ WHtR } & High risk & 4.7 & $(3.3-6.7)$ & 5.6 & $(4.1-7.7)$ & 10.3 & $(8.4-12.5)$ & 10.7 & $(8.6-13.2)$ \\
\hline
\end{tabular}

CI; confidence interval.

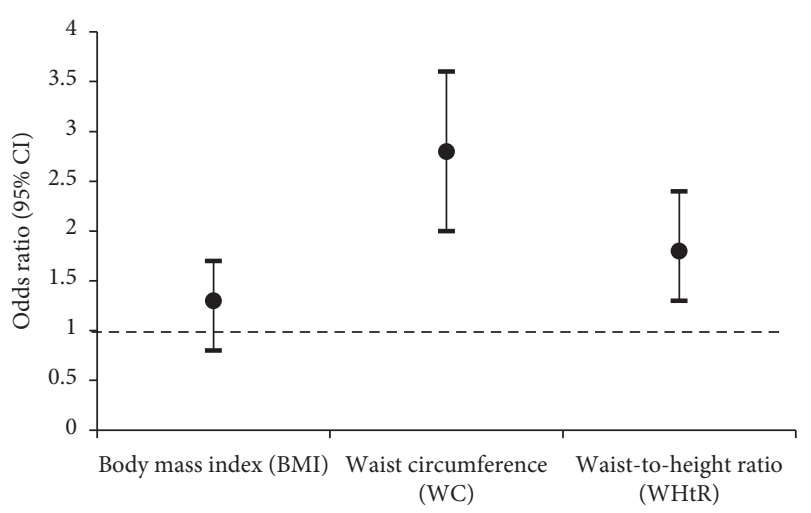

FIGURE 2: Odds of being BMI overweight/obese, central overweight/obese (WC), and being at "high risk" (WHtR $\geq 0.5)$ in 2020 when compared to 2010 .

quartiles of height z-score was $126.7 \mathrm{~cm}, 131.1 \mathrm{~cm}, 137.4 \mathrm{~cm}$, and $144.0 \mathrm{~cm}$, respectively.

Figure 3 shows the changes in the prevalence of BMI overweight/obesity in relation to height in males and females. For both surveys, the prevalence of BMI overweight/ obesity increased with increasing quartiles of height z-score. In 2020, the prevalence of BMI overweight/obesity was higher across all quartiles of height z-score than 2010. However, a significant difference in the prevalence of BMI overweight/obesity was observed between the two surveys only in the fourth quartile of height $\mathrm{z}$-score in females $\left(X^{2}=11.838, p=0.001\right)$. This was not significant for males $\left(X^{2}=0.143, p=0.391\right)$.

Figure 4 also shows that the prevalence of central overweight/obesity (WC) increased with increasing quartiles of height $\mathrm{z}$-score in both surveys for males and females. There were significant differences in the prevalence of central overweight/obesity (WC) between 2010 and 2020 in both males $\left(X^{2}=11.429, p=0.001\right)$ and females $\left(X^{2}=7.817\right.$, $p=0.005)$ in the fourth quartile of height $z$-score.

\section{Discussion}

This analysis set out to examine changes in measures of adiposity (BMI, WC, and WHtR) and also determine the prevalence of excess adiposity in relation to height over a 10year period in two groups of children in the North West Region of Cameroon.
This study confirms that there is no change in the adjusted prevalence of BMI overweight/obesity between the two surveys. However, the data show an increasing trend in both central overweight/obesity (WC) and WHtR $\geq 0.5$ among all children. This means central overweight/obesity is increasing more than BMI overweight/obesity. A previous study in Norway had shown an increase in trends of WC but not BMI over a 6-year period after adjusting for school type, tanner stage, and age [22]. Several studies in different countries have shown that the central obesity assessed using WC in children has been increasing over time. For instance, reports by Liang et al. [23], Griffiths et al. [24], and Suder et al. [25] showed that WC increased at a relatively faster rate than BMI among Chinese, British, and Polish children, respectively. Also, central obesity assessed using central skinfold thickness was found to increase at a faster rate than BMI in Brazilian children [26]. In addition, a study by Freedman et al. [27] indicated that secular increases in WC observed in US children from 1998-1994 through 2011-2012 are independent of changes in BMI. As observed in this study, other authors had also indicated that this increase in WC was more in girls than in boys $[24,26]$. However, a study in Brazilian children reported a higher increase in central obesity in boys than girls over a five-year period [28]. The increase in waist circumference observed in this study could be due to a transition to unhealthy eating habits, increase in sedentary lifestyle, and physical inactivity among children in subSaharan Africa [4]. In fact, a previous study in the NWR of Cameroon had indicated that an increase in sedentary lifestyle ( $>3$ hours/day) was associated with a $1.37 \mathrm{~mm}$ increase in triceps skinfold thickness [29]. The prevalence of WHtR $\geq 0.05$ in our study also increased in both males and females during the 10 -year period. This is similar to a previous study, which indicated that WHtR increased over time in three different samples of children, especially in girls [24]. Our analysis indicated that there is no significant change in the prevalence of BMI overweight/obesity over time. This is contrary to a report by Lazzeri et al. [30], which indicated that BMI overweight/obesity decreased over a ten-year period in Tuscan school children. The authors highlighted different initiatives that could have contributed to the decrease including official dietary guidelines, nutrition recommendations, national surveillance, and programmes aimed at encouraging fruit and vegetable intake in children. Cameroon is yet to attain the WHO nutrition 


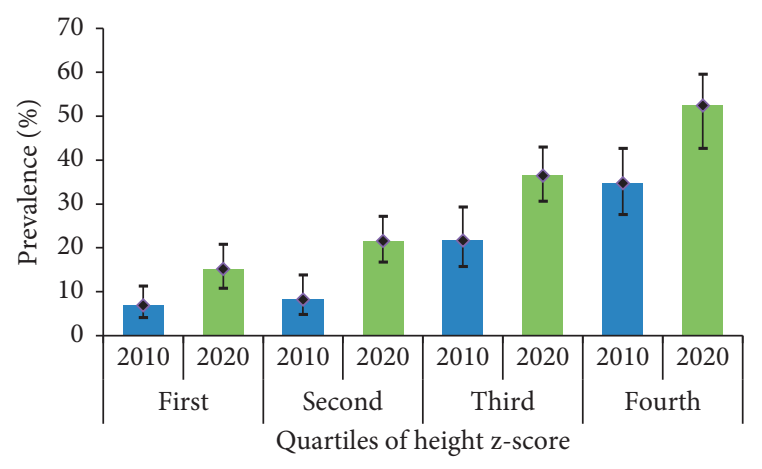

(a)

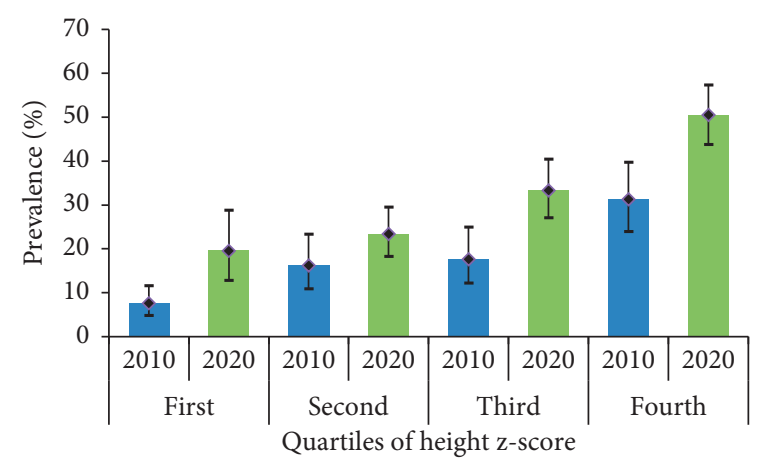

(b)

FIGURE 3: Adjusted prevalence (\%, 95\% CI) of BMI overweight/obesity across quartiles of height z-score in males (a) and females (b).

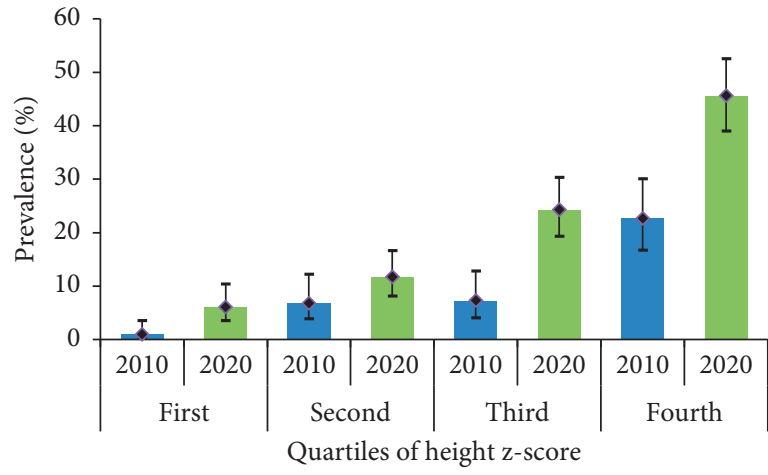

(a)

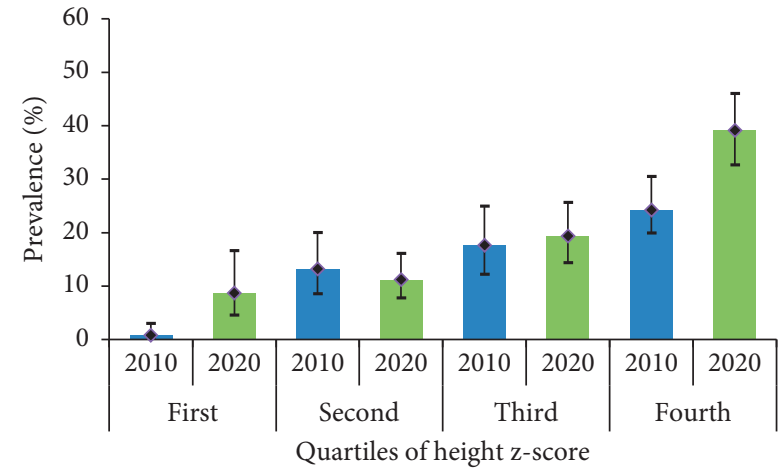

(b)

Figure 4: Adjusted prevalence (\%, 95\% CI) of central overweight/obesity across quartiles of height z-score in males (a) and females (b).

targets that concern overweight/obesity [5], and our analysis has confirmed that the children are now having a more centralized distribution of body fat.

Logistic regression indicated gender disparities in the odds of being overweight/obese (BMI), central overweight/ obese (WC), and being "at risk" (WHtR $\geq 0.5)$ over time. However, when the whole sample was taken into consideration, the odds of central overweight/obesity (WC) and WHtR $\geq 0.5$ significantly increased over time. However, the increase in odds of BMI overweight/obesity was not significant. This increase in risk of central overweight/obesity in our sample is concerning. This is because evidence indicates that children with central overweight/obesity are at risk of developing adverse health outcomes early in life including cardiovascular disease and type 2 diabetes [9]. It is important to point out that the authors of the abovementioned studies took WC measurements at different anatomical sites, which could account for the differences observed. However, a previous study in children had shown that the relationships between WC (measured at four different anatomical sites) and cardiometabolic risk factors were similar within race and gender groups [31].

This analysis has confirmed that the prevalence of BMI overweight/obesity and central overweight/obesity (WC) increased with increasing quartiles of height $\mathrm{z}$-score in the two surveys. The highest prevalence was recorded amongst the tallest-for-age children. Also, the prevalence of BMI overweight/obesity and central overweight/obesity was higher in 2020 than 2010 within each quartile of height z-score.

A previous analysis in the NW Region of Cameroon had shown that children who have a higher height-for-age accumulated more adiposity [11]. Our current analysis indicates that this association has persisted over time when BMI and $\mathrm{WC}$ are used to assess adiposity suggesting that tallness could predict both the level and distribution of adiposity in children. Previous evidence from other countries has shown that taller children tend to be overweight/obese [32-34]. Also, a report had shown higher adiposity levels amongst the tallest UK children from different age groups [35]. However, the BIA equipment used in the study had been shown to underestimate adiposity in children.

The height-adiposity relationship observed in this study could be explained from a nutrition perspective. There is evidence suggesting that high protein intake early in life is associated with increased risk of obesity [36], and the high protein intake has been suggested to contribute to an imbalance in some hormonal levels in obese children. For instance, a previous report indicated that obese children have higher levels of insulin-like growth factor 1 (IGF-1) and lower levels of growth hormone (GH) [37], all of which result from high protein intake [38]. The high levels of IGF-1 promote adipose tissue hyperplasia and growth [39]. Also, the deceased levels of GH result in a decrease in 
its lipolytic effect [37], which results in an increase in adiposity levels.

However, the source of protein and the timing need to be considered because a study had indicated that diary protein at the age of 1 year is associated with higher levels of adiposity at age 7 years [38]. Also, a report had suggested that this relationship between height and adiposity could result from an accumulation of body fat at levels higher than that required for linear growth [33]. In addition, previous reports had indicated that taller children were fatter and more insulin resistant $[40,41]$, suggesting that insulin resistance could explain to some extent the higher levels of adiposity observed among the tallest children in our study. However, this needs further investigation.

This study has limitations worth mentioning. Our data are from two different cross-sectional surveys and can be used neither to establish causality nor in the prediction of future trends. Also, in the absence of reference data for WC in our setting, we used the UK growth reference data for WC in our analysis to define central overweight/obesity, which may not be reflective of Cameroonian children. In addition, we could not adjust for other important variables that could influence adiposity such as puberty and dietary habits. Thus, we do not have evidence to indicate whether our current observations are as much a result of a high protein intake in our sample.

The current study had strong points worth mentioning. Our data have provided a glimpse of trends over the last decade for the first time in Cameroon school-age children. Also, other objective measures of adiposity (WC and WHtR) were included, which could be used alongside BMI. In addition, we included design/socioeconomic variables (class and school type) in our analysis, and this avoided an overestimation of the differences observed between the two surveys.

\section{Conclusions}

To conclude, the proportion of children with central overweight/obesity has significantly increased. The odds of central overweight/obesity (WC), and being "at risk" according to WHtR, has increased over ten years, and this is concerning. Our study provides baseline data for future comparisons. We propose the establishment of a surveillance system and schoolbased preventive measures for children. We also recommend the use of waist circumference as an additional tool for health promotion and early diagnosis of central overweight/obesity. The prevalence of BMI overweight/obesity and central overweight/obesity (WC) was the highest amongst the tallest children, and this association has persisted over time. Thus, we are suggesting that standing height could be used in the clinical setting to predict adiposity. However, longitudinal studies will be needed in the future to ascertain our claim. Also, future studies are needed to identify the different biological, environmental, and behavioral drivers of adiposity in order to reduce the risk of chronic diseases.

\section{Data Availability}

The data used to support the findings of this study are available from the corresponding author upon reasonable request.

\section{Conflicts of Interest}

The authors declare no conflicts of interest regarding the publication of this article.

\section{Acknowledgments}

This study was conducted by the Nutrition and Health Research Group (NHRG) in Bamenda, Cameroon. They are also grateful to the administration of the different schools as well as the pupils for accepting to participate in this study.

\section{References}

[1] M. di Cesare, M. Sorić, P. Bovet et al., “The epidemiological burden of obesity in childhood: a worldwide epidemic requiring urgent action," BMC Medicine, vol. 17, no. 1, p. 212, 2019.

[2] NCD-RisC, "Worldwide trends in bod mass index, underweight, overweight, and obesity from 1975 to 2016: a pooled analysis of 2416 population-based measurement studies in 128.9 million children, adolescents and adults," Lancet, vol. 390, pp. 2627-2642, 2017.

[3] N. Marie, T. Fleming, and M. Robinson, "Global, regional and national prevalence of overweight and obesity in children and adults 1980-2013: a systematic analysis," Lancet, vol. 384, pp. 766-781, 2014.

[4] F. K. Assah, U. Ekelund, S. Brage, J. C. Mbanya, and N. J. Wareham, "Urbanization, physical activity and metabolic health in sub-Saharan Africa," Diabetes Care, vol. 34, no. 2, pp. 491-496, 2011.

[5] 2020 Global Nutrition Report, Action on Equity to End Malnutrition, https://globalnutritionreport.org/reports/2020global-nutrition-report/, Development Initiatives Poverty Research Ltd, Bristol, UK, 2020, https://globalnutritionreport. org/reports/2020-global-nutrition-report/.

[6] S. K. Muthuri, C. E. Francis, L. J. M. Wachira et al., "Evidence of an overweight/obesity transition among school-aged children and youth in Sub-Saharan Africa: a systematic review," PLoS One, vol. 9, no. 3, Article ID e92846, 2014.

[7] F. Dangardt, M. Charakida, G. Georgiopoulos et al., "Association between fat mass through adolescence and arterial stiffness: a population-based study from the avon londitudinal study of parents and chidren," Lancet Child Adolesc Health, vol. 3, no. 3, pp. 474-481, 2019.

[8] R. Kuciene and V. Dulskiene, "Associations between body mass index, waist circumference, waist-to-height ratio, and high blood pressure among adolescents: a cross-sectional study," Scientific Reports, vol. 9, no. 9493, 2019.

[9] X. Fang, J. Zuo, J. Zhou et al., "Childhood obesity leads to adult type 2 diabetes and coronary artery diseases. A 2-sample mendelian randomization study," Medicine, vol. 98, no. 32, Article ID e16825, 2019.

[10] P. C. F. Wamba, J. E. Oben, and K. Clanflone, "Prevalence of overweight, obesity and thinness in Cameroon urban children and adolescents," Journal of Obesity, vol. 2013, Article ID 737592, 9 pages, 2013.

[11] L. K. Navti, U. Ferrari, E. Tange, K. G. Parhofer, and S. B. Pozza, "Height-obesity relationship in school children in Sub-Saharan Africa: results of a cross sectional study in Cameroon," BMC Research Notes, vol. 8, no. 1, p. 98, 2015.

[12] S. Tchoubi, J. Sobngwi-Tambekou, J. J. N. Noubiap, S. L. Asangbeh, B. A. Nkoum, and E. Sobngwi, "Prevalence and risk factors of overweight and obesity among children 
aged 6-59 months in Cameroon: a multistage, stratified cluster sampling nationwide survey," PLoS One, vol. 10, no. 12, Article ID e0143215, 2015.

[13] E. W. Demerath, C. M. Schubert, L. M. Maynard et al., "Do changes in body mass index percentile reflect changes in body composition in children? data from the fels longitudinal study," Pediatrics, vol. 117, pp. 487-495, 2006.

[14] J. J. Reilly, M. L. Wilson, C. D. Semmerbell, and D. C. Wilson, "Obesity: diagnosis and treatment; evidence based answers to common questions," Archives of Diseases in Childhood, vol. 86, pp. 392-395, 2001.

[15] E. Rodríguez-Rodríguez, C. Palmeros-Exsome, C. PalmerosExsome, A. M. López-Sobaler, and R. M. Ortega, "Preliminary data on the association between waist circumference and insulin resistance in children with a previous diagnosis," European Journal of Pediatrics, vol. 170, no. 1, pp. 35-43, 2011.

[16] M. Hara, E. Saitou, F. Iwata, T. Okada, and K. Harada, "Waistto-height ratio is the best predictor of cardiovascular disease risk factors in Japanese school children," Journal of Atherosclerosis and Thrombosis, vol. 9, no. 3, pp. 127-132, 2002.

[17] S. K. Mehta, "Waist circumference to height ratio in children and adolescents," Clinical Pediatrics, vol. 54, no. 7, pp. 652-658, 2015.

[18] E. Whitley and J. Ball, "Statistics review 4: sample size calculations," Critical Care, vol. 6, no. 4, pp. 335-341, 2002.

[19] H. McCarthy, K. Jarrett, and H. Crawley, "The development of waist circumference percentiles in British children aged 5.0 to 16.9 years," European Journal of Clinical Nutrition, vol. 55, no. 10, pp. 902-907, 2001.

[20] E. Borghi, M. de Onis, C. Garza et al., "Construction of the world health organization child growth standard: selection of methods for attained growth curves," Statistics in Medicine, vol. 25, no. 2, pp. 247-265, 2006.

[21] P. Brambilla, G. Bedogni, M. Heo, and A. Pietrobelli, "Waist circumference-to-height ratio predicts adiposity better than body index in children and adolescents," International Journal of Obesity, vol. 37, no. 7, pp. 943-946, 2013.

[22] E. Kolle, J. Steene-Johannessen, I. Holme, L. B. Andersen, and S. A. Anderssen, "Secular trends in adiposity in Norwegian 9 year olds from 1999-2000 to 2005," BMC Public Health, vol. 9, no. 1, p. 389, 2009.

[23] Y. J. Liang, B. Xi, A. Q. Song, J. X. Liu, and J. Mi, “Trends in general and abdominal obesity among Chinese children and adolescents 1993-2009," Pediatric Obesity, vol. 7, no. 5, pp. 355-364, 2012.

[24] C. Griffiths, P. Gately, P. R. Marchant, and C. B. Cooke, "Cross sectional comparisons of BMI and waist circumference of British children: mixed public health messages," Obesity, vol. 20, no. 6, pp. 1258-1260, 2012.

[25] A. Suder, A. Gomula, and S. Koziel, "Central overweight and obesity in polish scholl children aged 7-18 years: secular changes of waist circumference between 1966 and 2012," European Journal of Pediatrics, vol. 176, no. 7, pp. 909-916, 2017.

[26] D. S. Freedman, B. K. Kit, and E. S. Ford, "Are the recent secular increases in waist circumference among children and adolescents independent of changes in BMI?" PLoS One, vol. 10, no. 10, p. 10, Article ID e0141056, 2015.

[27] D. B. Leal, M. A. A. de Assis, D. A. González-Chica, F. F. da Costa, D. F. de Andrade, and A. S. Lobo, "Changes in total and central adiposity and body fat distribution among 7-10 yearold school children in Brazil," Public Health Nutrition, vol. 18, no. 12, pp. 2105-2114, 2014.

[28] D. B. Leal, M. A. A. de Assis, D. A. González-Chica, and F. F. da Costa, “Trends in adiposity in Brazilian 7-10-year-old school children: evidence for increasing overweight but not obesity between 2002 and 2007," Annals of Human Biology, vol. 41, no. 3, pp. 255-262, 2014.

[29] L. K. Navti, M. B. Atanga, and L. L. Niba, "Association of out of school physical activity, sedentary lifestyle and socioeconomic status with weight status and adiposity of Cameroon children," BMC Obesity, vol. 4, no. 1, p. 35, 2017.

[30] G. Lazzeri, D. Panatto, A. Pammolli, E. Azzolini, and R. Simmi, "Trends in overweight and obesity prevalence in Tuscan school children (2002-2012)," Public Health Nutrition, vol. 18, pp. 3078-3085, 2015.

[31] D. M. Harrington, A. E. Staiano, S. T. Broyles, A. K. Gupta, and P. T. Katzmarzyk, "Waist circumference measurement site does not affect relationships with visceral adiposity and cardiometabolic risk factors in children," Pediatric Obesity, vol. 8, no. 3, pp. 199-206, 2012.

[32] D. S. Freedman, L. K. Khan, M. K. Serdula, W. H. Dietz, S. R. Srinivasan, and G. S. Berenson, "Inter-relationships among childhood BMI, childhood height, and adult obesity: the Bogalusa heart study," International Journal of Obesity and Related Metabolic Disorders: Journal of the International Association for the Study of Obesity, vol. 28, pp. 10-16, 2004.

[33] D. S. Freedman, J. C. Thornton, Z. Mei et al., "Height and adiposity in children," Obesity Research, vol. 12, no. 5, pp. 846-853, 2004.

[34] I. E. Buchan, P. E. Bundred, D. J. Kitchiner, and T. J. Cole, "Body mass index has risen more steeply in tall than short 3 year olds: serial cross-sectional surveys 1988-2003," International Journal of Obesity, vol. 31, no. 1, pp. 23-29, 2007.

[35] L. K. Navti, D. Samani-Radia, and H. D. McCarthy, "Children's body fatness and prevalence obesity in relation to height-for-age," Annals of Human Biology, vol. 41, pp. 223228, 2014.

[36] A. L. Gunther, A. E. Buyken, and A. Kroke, "Protein intake during the period of complimentary feeding and early childhood and their association with BMI and body fat percentage at age 7," American Journal of Clinical Nutrition, vol. 85, pp. 1626-1633, 2008.

[37] M. Scacchi, A. Pincelli, and F. Cavagnini, "Growth hormone in obesity," International Journal of Obesity, vol. 23, no. 3, pp. 260-271, 1999.

[38] A. L. Günther, T. Remer, A. Kroke, and A. E. Buyken, "Early protein intake and later obesity risk: which protein sources and at which time points throughout infancy and childhood are important for body mass index and body fat percentage at 7 years of age?" The American Journal of Clinical Nutrition, vol. 86, no. 6, pp. 1765-1772, 2007.

[39] S. de Ferranti and D. Mozaffarian, "Growth hormone in obesity," Clinical Chemistry, vol. 54, no. 6, pp. 945-955, 2008.

[40] B. S. Metcalf, J. Hosking, A. E. Frémeaux, A. N. Jeffery, L. D. Voss, and T. J. Wilkin, "BMI was right all along: taller children really are fatter (implications of making childhood BMI independent of height)," International Journal of Obesity, vol. 35, no. 4, pp. 541-547, 2011.

[41] A. Bavdekar, C. S. Yajnik, C. H. Fall et al., "Insulin resistance syndrome in 8-year-old Indian children. small at BIRTH, big at 8 years, or both," Diabetes, vol. 48, no. 12, pp. 2422-2429, 1999. 